\title{
Modalities in managing postherpetic neuralgia
}

The First Affiliated Hospital of Chongqing Medical University, Chongqing Shi, China

Meera Shrestha and Aijun Chen

\begin{abstract}
Postherpetic neuralgia (PHN) is the most troublesome side effect of Herpes Zoster (HZ), which mainly affects the elderly and immunocompromised populations. Despite the current advancement of treatments, PHN persists in many individuals influencing their daily activities and reducing their quality of life. Anticonvulsants, antidepressants, topical therapies including lidocaine and capsaicin, and opioids, are the most widely used therapies for the treatment of PHN. These medications come with their adverse effects, so they should be used carefully with the elderly or with patients with significant comorbidities. Other measures like botulinum toxin, nerve blocks, spinal cord stimulation, and radiofrequency have also contributed significantly to the management of PHN. However, the efficacy, safety, and tolerability of these invasive methods need to be carefully monitored when administering them. Early diagnosis and early initiation of treatment can reduce the burden associated with PHN. The zoster vaccine has effectively reduced the incidence of HZ and PHN. In this article, we discuss the treatment options available for the management of PHN, mainly focusing on the efficacy and safety of different therapeutic modalities. (Korean J Pain 2018; 31: 235-43)
\end{abstract}

Key Words: Aged; Anticonvulsants; Antidepressants; Botulinum toxin; Capsaicin; Herpes zoster vaccination; Incidence; Nerve block; Opioids; Postherpetic neuralgia; Quality of life; Spinal cord stimulation.

\section{INTRODUCTION}

Postherpetic neuralgia (PHN) is a chronic neuropathic pain syndrome, one of the significant complication following an infection of herpes zoster (HZ) also known as shingles [1-3]. HZ results from the reactivation of the dormant varicella-zoster virus (VZV), which resides latently in the sensory ganglion of the cranial nerves or the dorsal root ganglion of the spinal cord after the primary varicella infection, or chickenpox, earlier in life [4,5]. HZ symptoms resolve after a few weeks, but the pain caused by the sen- sory damage persists for months in the affected area, and is known as postherpetic neuralgia [6].

A systematic review conducted in 2014, reported that an estimated incidence of $\mathrm{HZ}$ ranged between 3-5/1000 person/year in Europe, North America, and Asia-Pacific with a rise above 50 years of age, and the occurrence of PHN in HZ patients is 5\%-30\% [7]. In another study, Chen et al. [8] estimated that in Asia-Pacific alone, the incidence of $\mathrm{HZ}$ is 3-10/1000 person/year which rises steeply above age 40 and peaks between 70-80 years and the incidence of $\mathrm{PHN}$ is $10 \%-25 \%$. The PHN incidence is $10 \%$ in

Received March 20, 2018. Revised April 17, 2018. Accepted May 14, 2018.

Correspondence to: Aijun Chen

The First Affiliated Hospital of Chongqing Medical University, Youyi Road 1, Yuzhong District, Chongqing 400016, China

Tel: +0086-68811360, E-mail: 3034203217@qq.com

(c) This is an open-access article distributed under the terms of the Creative Commons Attribution Non-Commercial License (http:// creativecommons.org/licenses/by-nc/4.0/), which permits unrestricted non-commercial use, distribution, and reproduction in any medium, provided the original work is properly cited.

Copyright (c) The Korean Pain Society, 2018 
people over 40 years, $20 \%-50 \%$ of people over 60 years and rarely seen in people less than 30 years. The incidence of PHN increases with advanced age and decreased immunity. Thus, it is mostly seen in the elderly [1,2].

In addition to older age, prodromal pain, the severity of acute HZ, the intensity of acute pain and ophthalmic involvement with keratitis and other intraocular complications are the principal risk factors associated with the development of PHN [9]. Females are more likely to be affected by PHN than their male counterparts [10].

After the resolution of chickenpox, which usually occurs in childhood, the VZV remains dormant in the sensory ganglion for many years. VZV reactivates due to the decline or disorder of specific cell-mediated immunity to VZV brought by aging, immunosuppression for managing cancer, hemopathies, solid organ transplantation, or other immunosuppressive medical treatments [1,11].

HZ manifests as an erythematous, maculopapular rash followed by formation of clear vesicles, pustules and finally crusts and scabs $[6,9,11]$. HZ lesions do not cross the midline; it is unilateral and in most cases affects a single dermatome $[3,11]$. The patient complains of itching, tingling, and mild to severe pain associated with the rash. Skin lesions heal within 2-4 weeks.

PHN is the most frequent complication of HZ. It is described as pain persisting for 3 months or more after the onset of rash in the same affected dermatome. In most of the cases, pain improves progressively; only in 1-2\% pain persists for years $[9,11,12]$. The pain of PHN is categorized into three types: 1) constant pain (often described as continuous burning, aching, throbbing), 2) intermittent pain (often described as stabbing, shooting, electric-shock-like pain), 3) stimulus-evoked pain such as allodynia (pain provoked by non-painful stimulus such as light touch) or hyperalgesia (exaggerated response to painful stimulus) [3,6,12].

PHN interferes with the patient's daily activities, such as dressing, bathing, eating, shopping, and traveling, leading to a reduced quality of life, psychological stress, and physical disabilities $[3,13]$. This article aims to summarize the current treatment options and new developments in the treatment of PHN [14].

\section{MAIN BODY}

\section{Anticonvulsants}

Since the 1960s antiepileptic drugs (also known as anticonvulsants) have been used in pain management, though their use is mainly confined to neuropathic pain $[15,16]$. Anticonvulsants like gabapentin and pregabalin are recommended and approved by the Food and Drug Administration (FDA) as the first line of treatment for PHN $[2,14]$.

\section{1) Gabapentin}

Gabapentin was approved by the FDA for the treatment of PHN in adults in 2004 [17]. Gabapentin is structurally related to GABA neurotransmitter. It acts by binding to the $\alpha 2-\delta$ site of voltage-gated calcium channels, modulating the influx of calcium and thereby resulting in the reduced release of excitatory neurotransmitters [18]. Gabapentin (Neurontin ${ }^{\circledR}$; Pfizer, New York, NY) is started at $300 \mathrm{mg}$ daily and slowly titrated up to $1800 \mathrm{mg}$ daily (600 mg TID) as needed for pain relief [17]. The bioavailability of gabapentin is inversely proportional to its dose. A dose of more than $1800 \mathrm{mg}$ does not significantly benefit in pain relief, but only contributes to adverse effects such as dizziness (28\%), somnolence (21\%) [17], peripheral edema, ataxia or gait disturbance, and diarrhea [18]. In spite of its efficacy, gabapentin has some limitations. It requires frequent daily dosing due to its short half-life (5-7 h) resulting in low patient compliance. It requires long titration periods to achieve a therapeutic dose and has limited absorption time.

Two types of extended-release gabapentin formulations were developed to improve the efficacy, safety, and tolerability of PHN therapy, and to overcome the long titration periods [2]. Gastro-retentive gabapentin (Gralise ${ }^{\circledR}$; Depomed, Newark, CA), was approved by the FDA in 2011 [19]. Gastroretentive gabapentin has a polymer-based drug delivery system and its bioavailability increases with a meal. The drug expands in the stomach when it comes in contact with the gastric juice and is retained in the stomach, slowly releasing the medicine for more than 10 hours, allowing for more absorption time [20]. This formulation of a once daily dose is convenient for the patient, and the recommended maximum dose of $1800 \mathrm{mg}$ can be reached within 2 weeks. Starting at $300 \mathrm{mg}$ with the evening meal, 
it is titrated by $300 \mathrm{mg}$ on day 2, 3, 7, 11, and 15, and maintained at $1800 \mathrm{mg}$ after day 15 [19].

Gabapentin enacarbil (Horizant ${ }^{\circledR}$; Arbor Pharmaceuticals, LLC Atlanta, GA), was approved by the FDA in 2012 [21]. Gabapentin enacarbil is an alkyl carbamate prodrug of gabapentin, which has an absorption profile stated to provide predictable bioavailability and sustained proportional dose exposure [22]. Starting at $300 \mathrm{mg}$ daily for 3 days, it is increased to $600 \mathrm{mg}$ twice daily on the 4th day and maintained at $1200 \mathrm{mg}$ daily until pain relief [21]. The adverse effects of gastro-retentive gabapentin in clinical trials were reported to be $11 \%$ for dizziness and $5 \%$ for somnolence [19], and for gabapentin enacarbil they were reported to be $22 \%$ for dizziness and $27 \%$ for somnolence [21].

\section{2) Pregabalin}

Pregabalin (Lyrica $^{\circledR}$; Pfizer, NY, NY) was approved by the FDA for the treatment of PHN in 2005 [23]. It acts similarly to that of gabapentin, binding to calcium channels, modulating the influx of calcium, and influencing neurotransmitter release. It is more potent than gabapentin, so it is used at a lower dose [16]. The initial dose is 150 $\mathrm{mg} /$ day in divided doses, and can be increased to 300 $\mathrm{mg} /$ day in a week depending on safety and tolerability. The maximum dose of $600 \mathrm{mg} /$ day can be reached in 2-4 weeks' time. The reported adverse effects for pregabalin in clinical trials were $26 \%$ for dizziness and $16 \%$ for somnolence [23].

A study conducted in Japan reported that the analgesic property of pregabalin was 6 times that of gabapentin in PHN in terms of efficacy in dosage conversion [24]. However, dosage should be increased gradually and carefully to prevent adverse effects in spite of pain reduction $[16,24]$.

\section{Antidepressants}

Many anti-depressants have been used for neuropathic pain caused by PHN since the early 1980s at a lower dose which provides the only analgesia and not relief from depression [2,14]. Tricyclic antidepressants (TCA) such as amitriptyline, nortriptyline, and desipramine, have been studied and commonly used as an off-label treatment for patients with PHN, although not approved by the FDA [5].
TCAs provide analgesia by inhibiting the reuptake of serotonin and norepinephrine neurotransmitters at the presynaptic nerve terminals thereby decreasing the sensory perception between the brainstem and spinal cord $[4,10]$. They also act by blocking the sodium channels and $\alpha$-adrenergic receptors modulating the descending pain pathway [1]. TCAs should be started at a low dose of 10-25 $\mathrm{mg}$ at bedtime and gradually titrated every $3-7$ days by 10-25 mg as tolerated by the patient up to a maximum dose of $150 \mathrm{mg}$ daily. TCA treatment is tapered off by the 6 th to 8th week with 1-2 weeks of the maximum tolerated dose [25]. Clinical trials and meta-analysis demonstrated that Number Needed to Treat (NNT) with TCAs in the management of PHN was 2.1-2.6 [26].

Although TCAs have proved their efficacy in the management of PHN, they have a relatively slow onset of action and are often associated with adverse effects such as sedation, dry mouth, blurred vision, constipation, urinary retention, QT interval prolongation, sexual dysfunction, and postural hypotension [27]. A baseline ECG is advised before beginning treatment especially for elderly patients and for those with a history of cardiac disease or hypokalemia [10]. Caution must be taken when prescribing TCAs to patients who are at risk of suicide and overdose because of the risk of fatal cardiac dysrhythmias and serotonin syndrome [25].

Amitriptyline is the most widely prescribed and studied TCA for the treatment of PHN but is poorly tolerated by some because of its much higher anticholinergic effects.

Nortriptyline and desipramine are better tolerated with greater efficacy than amitriptyline as demonstrated by clinical trials and evidence [14,28].

\section{Topical lidocaine}

Lidocaine is a local anesthetic and can provide surface analgesia when applied topically [14]. To facilitate transfer across the uninjured skin, lidocaine is formulated as a plaster for the treatment of chronic pain such as PHN [29]. The medicated plaster (Versatis ${ }^{\circledR}$, Grunenthal Ltd, Stokenchurch, UK) is a $10 \mathrm{~cm} \times 14 \mathrm{~cm}$ hydrogel adhesive containing $700 \mathrm{mg}$, 5\% lidocaine attached to a non-woven polyester backing [30].

The plaster is applied once daily to the undamaged skin for $12 \mathrm{~h}$ with a plaster-free interval of $12 \mathrm{~h}$. A total of three plasters can be used simultaneously depending on 
the size of the painful area. The lidocaine hydrogel plaster provides an immediate cooling sensation and acts as a mechanical barrier.

Pharmacologically, it works by partially inhibiting the voltage-gated calcium channels thereby stabilizing the neuronal membrane potential on $\mathrm{A} \delta$ and $\mathrm{C}$ fibers resulting in a reduced discharge of ectopic activity in damaged afferent pain receptors [31].

After application of the plaster, lidocaine is released continuously providing analgesia [29]. Only $3 \%$ of the lidocaine reaches the systemic circulation, which is well below toxic concentrations in individuals with a healthy cardiac, renal, and hepatic function [32]. The liver extensively metabolizes lidocaine and it is excreted by the kidney; less than $10 \%$ is excreted unchanged. In healthy individuals, the elimination half-life of lidocaine is $7.6 \mathrm{~h}$ [30].

The adverse effects observed after lidocaine plaster treatment are only local skin reactions described as pruritus, erythema, rash, a burning sensation, and edema [33]. The $5 \%$ medicated lidocaine is well tolerated by individuals of any age with minimal adverse effects [33]. A clinical trial demonstrated that $5 \%$ lidocaine was better tolerated than systemic treatment with pregabalin [34].

\section{Topical capsaicin}

Capsaicin is an irritant ingredient found in hot chili peppers of the genus Capsicum. It is a selective agonist of TRPV1 channels located in the nociceptors nerve fibers of the skin. Exposure to capsaicin activates TRPV1 which causes an influx of calcium and also inhibits the electron-chain transport resulting in a loss of cellular integrity and defunctionalization of nociceptor nerve fibers for a prolonged period [35].

Several studies demonstrated that low-dose capsaicin (0.025 to $0.075 \%$ ) formulations could only provide moderate pain relief and required multiple applications in a day [36]. A high concentration 8\% capsaicin transdermal patch (Qutenza $^{\circledR}$; Acorda Therapeutics Inc. Ardsley, NY) was introduced in 2009 which required only a single application for the treatment of neuropathic pain [37].

It was approved by the FDA for PHN treatment and must be applied by trained professionals in health care centers. A 2017 Cochrane review reported that high concentration topical capsaicin proved to be more efficient than the low concentrations in achieving excellent pain re- lief in people with PHN, after a single application [38].

The capsaicin patch is $14 \times 9 \times 20 \mathrm{~cm}$ in size containing $8 \%$ capsaicin $\left(640 \mathrm{mcg} / \mathrm{cm}^{2}\right)$ and a total of $179 \mathrm{mg}$ of capsaicin in a single patch [37]. The patch is used as a single application over the uninjured painful area, and is left in place for $60 \mathrm{~m}$. A single patch can provide pain relief for up to 3 months, and treatment can be repeated after 90 days if pain persists or returns [38].

Adverse effects such as application site burning, erythema, pain, dryness, edema, and pruritus were noticed [37]. The skin is usually pretreated with topical analgesic (lidocaine 4\%) to overcome the initial burning sensation felt on the application of the capsaicin patch [38]. Systemic absorption of capsaicin from the patch is very low. The epidermal or dermal layers absorbs only $1 \%$ of the capsaicin within 60 minutes of application. Exposure to capsaicin is proportional to the treatment area and duration of treatment [37]. Systemically absorbed capsaicin is metabolized by the cytochrome P450 enzyme present in the liver, while human skin plays a minor role in its metabolism [39].

\section{Opioids}

Despite its good analgesic effect, the use of opioids to treat neuropathic pain such as PHN is controversial owing to concerns about misuse, overdose, dependence, and addiction. Opioids are used as second-line or third-line agents for PHN [14]. Some physicians use it as an adjunct therapy at a lower dose to provide immediate pain relief, while the other first-line agents are being titrated to reach their therapeutic dose.

Opioids provide analgesia by modulating pain via various opioid receptors of the mu, kappa, and delta classes that are present both centrally and peripherally during an inflammatory response. These receptors coupled with inhibitory G-proteins, when activated, causes closure of voltage-gated calcium channels leading to potassium efflux and hyperpolarization, and decreases the production of cyclic adenosine monophosphate. These mechanisms result in a reduction of neuronal cell excitability and transmission of nociceptive impulses, thereby altering the response to pain [1].

Several clinical studies have demonstrated that opioids are useful in the management of neuropathic pain, including PHN. A randomized controlled trial in 2002 showed that 
opioids and TCAs could provide better pain relief than a placebo (38.2\%, $31.9 \%$, and $11.2 \%$ pain relief, respectively) [40]. The NNT for a $50 \%$ reduction in PHN pain with strong opioids like oxycodone and morphine was 2.5 and 2.7, respectively [26]. Some of the adverse effects of opioid usage include nausea, pruritus, drowsiness, constipation, and sedation. Constipation prophylaxis should be considered when prescribing opioids, as it is the only long-lived adverse effect. Opioids should be cautiously used in patients with a history of substance abuse.

\section{Tramadol}

Tramadol acts as a centrally acting weak opioid at the $\mu$ receptor. It also inhibits the reuptake of serotonin and norepinephrine. Thus, it has both the properties of an opioid and of TCAs. The maximum dose should not exceed $400 \mathrm{mg} /$ day in healthy individuals and not more than 300 $\mathrm{mg} / \mathrm{d}$ in older patients ( $>75$ years). It is started at a low dose of $50 \mathrm{mg}$ and gradually titrated in 3-7 days by 50-100 mg as tolerated by the individuals. It is given in divided doses of 2-4 times a day [25].

Tramadol is considered a mild opioid and has proven to be less effective in pain relief in PHN than other opioids, but it is better tolerated and a safer alternative. A multicenter, double-blind RCT conducted in 2003 demonstrated a higher efficacy and safety for tramadol than the placebo, and the NNT for tramadol was 4.8 [41]. Since it has a property of TCAs, tramadol may be a better option for $\mathrm{pa}^{-}$ tients with a history of substance abuse or cardiac problems which restrict the use of TCAs.

The adverse effects of tramadol are similar to that of opioids, such as nausea, somnolence, constipation, dizziness, headache, and vertigo. In higher doses, tramadol tends to increase the risk of seizures, so caution should be taken when using tramadol on patients with a history of seizures or those taking drugs to reduce the seizure threshold. Simultaneous use of serotonergic medications, especially selective serotonin reuptake inhibitors (SSRIs), increases the risk of serotonin syndrome [13,25].

\section{Botulinum Toxin A}

Botulinum Toxin A (BTX-A), a toxin secreted by Clostridium botulinum has been used clinically for the treatment of various diseases for decades. BTX-A can be used for treating dystonia, spasticity, brain paralysis, strabismus, and cosmetic procedures. BTX-A is also used for the management of chronic pain of a different origin. Recent studies have demonstrated the use of Botulinum Toxin A $(\mathrm{BTX}-\mathrm{A})$ in the treatment of neuropathic pain including PHN [14,42].

The mechanism of action in BTX-A in relieving pain is not fully understood; however, there are several theories regarding its mechanism. It mainly acts by inhibiting the release of pain mediators from the nerve terminals and dorsal root ganglions, reducing inflammation around the nerve endings, deactivating sodium channels, and exhibiting axonal transport [43].

One study investigated the effect of BTX-A on $58 \mathrm{pa}-$ tients who were suffering from PHN symptoms for 4-15 months. In this study, BTX-A was effective in reducing pain in $18(31 \%)$ cases and showed significant outcomes in 27 (46.6\%) cases. However, it was ineffective in the remaining 13 (22.4\%) patients [44]. The pain severity, the attack frequency, the duration of attacks was significantly lowered after treatment. Only 4 patients complained of pain at the injection site which vanished after a week without any treatment [44]. More detailed studies should be conducted on the therapeutic usage of BTX-A to be used as an alternative or as an adjunct to the treatment of PHN.

\section{Nerve block}

Different studies validate the efficacy and safety of sympathetic nerve blocks for the prevention and treatment of PHN [14]. A recent systematic review conducted in Korea summarized that an early nerve block cannot only relieve acute $\mathrm{HZ}$ pain, but can also prevent its sequelae, PHN [45]. In this study, the authors concluded that among the various nerve blocks, stellate ganglion blocks had a lesser effect in reducing the occurrence of PHN. However, somatic blocks including repeated or continuous epidural and paravertebral blocks prevented PHN and reduced its incidence [45].

The risk of developing hemodynamic changes after nerve blocks is most commonly seen in older adults. There are many studies which have reported the long-term pain relief of PHN by nerve blocks, but the quality of evidence is limited [10].

Intrathecal glucocorticoid injections have been proved 
effective in patients with intractable PHN when the above treatment measures fail. However, it cannot be used for PHN involving the trigeminal nerve. But its association with adverse events, such as the risk of arachnoiditis, aseptic meningitis, headache, and urinary retention, has limited its use [10].

\section{Neuromodulation}

Another treatment option, which is used recently for chronic pain conditions after the conservative management has failed, is neuromodulation. Neuromodulation via various methods including transcutaneous electrical nerve stimulation (TENS) [46], peripheral nerve stimulation (PNS) [47], Spinal Cord Stimulation (SCS), and radiofrequency in combination with conservative treatment has contributed to the prevention of PHN [48-50].

SCS is reported to be useful in treatment and prevention of PHN [49,51]. The higher medical cost of SCS and difficulty in providing appropriate stimulation is its major setback, especially in the thoracic region where the level of CSF is deep [49]. Pulsed radiofrequency (PRF) is considered more useful in comparison to continuous radiofrequency $(\mathrm{CRF})$ in spite of its effectiveness in pain relief [50]. In CRF treatment, due to prolonged exposure of the nerves to a higher temperature, there is an increased risk of thermal or nerve injuries [48-50]. PRF with pulsed/short bursts of $\mathrm{RF}$ is used with the temperature of the probe maintained at $42^{\circ} \mathrm{C}$ to overcome these complications $[48,49]$.

Scrambler therapy has proven to be effective for PHN treatment in several clinical trials although enough randomized controlled studies have not been established $[52,53]$. It is non-invasive and works by interfering with the pain signal transmission through patient-specific $\mathrm{cu}-$ taneous electro-stimulation [52,53]. This therapy alleviates pain by modulating pain information to non-pain information [52]. However, extensive and definitive randomized controlled trials are required to investigate the efficacy of neuromodulation methods to reduce pain from PHN [46-53].

\section{Vaccination}

Administration of zoster vaccine in immunocompetent adults aged 60 or older is recommended by the United States Advisory Committees on Immunization Practices (ACIP) to reduce the incidence of $\mathrm{HZ}$ and prevention of PHN [54]. Zostavax ${ }^{\circledR}$ (Merck \& Co., Inc., Kenilworth, NJ) a live attenuated zoster vaccine was approved by the FDA in 2006 to prevent HZ and its associated complications [55]. It is given to individuals 50 years or older. It is not in-

Table 1. Treatment Summary for Postherpetic Neuralgia

\begin{tabular}{|c|c|}
\hline First Line Agents [14] & $\begin{array}{ll}\text { Anticonvulsants: } & \text { Antidepressants: } \\
\text { Gabapentin } & \text { Nortriptyline, desipramine, } \\
\text { Pregabalin } & \text { (amitriptyline, imipramine) }\end{array}$ \\
\hline Second Line Agents [14] & $\begin{array}{l}\text { Topical lidocaine } \\
\text { Topical capsaicin } \\
\text { Tramadol } \\
\text { Reason for them being second line is a low quality of } \\
\text { evidence (lidocaine), a relatively small effect size (topi } \\
\text { cal capsaicin), or lower tolerability or safety (tramadol). } \\
\text { Topical agents can be used at any time for focal pain }\end{array}$ \\
\hline Third Line Agents [14] & $\begin{array}{l}\text { Opioids } \\
\text { Botulinum Toxin A }\end{array}$ \\
\hline Invasive or Non-invasive Methods & $\begin{array}{l}\text { Nerve blocks } \\
\text { Neuromodulation } \\
\text { Nerve stimulation } \\
\text { Radiofrequency } \\
\text { Scrambler therapy }\end{array}$ \\
\hline Combination Therapy & $\begin{array}{l}\text { Various combination of above treatments are used to } \\
\text { provide pain relief to patients }\end{array}$ \\
\hline
\end{tabular}


dicated for the treatment of HZ, PHN, or as prevention against primary varicella infection [55].

The adverse effect reported after zoster vaccination is minor injection site reactions. Zoster vaccine successfully reduced the incidence of $\mathrm{HZ}$ and the burden associated with HZ, as well as the risk of the occurrence of PHN. Studies regarding the long-term protection of zoster vaccine are ongoing.

\section{CONCLUSIONS}

PHN is a complicated and burdensome neuropathic pain, which influences the individual's daily function and quality of life. Several agents and methods are available to provide relief from PHN symptoms (Table 1) [14].

Health professionals play a key role in recognizing the symptoms early and thereby providing better available treatment options, according, to the individual's therapeutic preferences. Therapies are given individually or in combination to produce efficient outcomes with fewer side effects.

The most widely used combination therapy, gabapentinoids with topical analgesics, are effective and well tolerated. For patients who continue to have intractable pain even after conservative management, invasive interventional techniques are applied.

Whatever the method, the primary task is to administer appropriate pain-relieving measures for better outcomes in patients. Early management increases the chances of complete pain relief from PHN [56].

Vaccination is also a useful measure to prevent HZ, the root cause of PHN.

\section{REFERENCES}

1. Gan EY, Tian EA, Tey HL. Management of herpes zoster and post-herpetic neuralgia. Am J Clin Dermatol 2013; 14: 77-85.

2. Massengill JS, Kittredge $J L$. Practical considerations in the pharmacological treatment of postherpetic neuralgia for the primary care provider. J Pain Res 2014; 7: 125-32.

3. Mallick-Searle T, Snodgrass B, Brant JM. Postherpetic neuralgia: epidemiology, pathophysiology, and pain management pharmacology. J Multidiscip Healthc 2016; 9: 447-54.

4. Nalamachu S, Morley-Forster P. Diagnosing and managing postherpetic neuralgia. Drugs Aging 2012; 29: 863-9.
5. Khadem T, Stevens $\vee$. Therapeutic options for the treatment of postherpetic neuralgia: a systematic review. J Pain Palliat Care Pharmacother 2013; 27: 268-83.

6. Hadley GR, Gayle JA, Ripoll J, Jones MR, Argoff CE, Kaye RJ, et al. Post-herpetic neuralgia: a review. Curr Pain Headache Rep 2016; 20: 17.

7. Kawai K, Gebremeskel BG, Acosta CJ. Systematic review of incidence and complications of herpes zoster: towards a global perspective. BMJ Open 2014; 4: e004833.

8. Chen LK, Arai H, Chen LY, Chou MY, Djauzi S, Dong B, et al. Looking back to move forward: a twenty-year audit of herpes zoster in Asia-Pacific. BMC Infect Dis 2017; 17 : 213.

9. Werner RN, Nikkels AF, Marinović B, Schäfer M, CzarneckaOperacz M, Agius AM, et al. European consensus-based (S2k) guideline on the management of herpes zoster guided by the European Dermatology Forum (EDF) in cooperation with the European Academy of Dermatology and Venereology (EADV), Part 1: diagnosis. J Eur Acad Dermatol Venereol 2017; 31: 9-19.

10. Jeon $\mathrm{YH}$. Herpes zoster and postherpetic neuralgia: practical consideration for prevention and treatment. Korean $J$ Pain 2015; 28: 177-84.

11. Bader MS. Herpes zoster: diagnostic, therapeutic, and preventive approaches. Postgrad Med 2013; 125: 78-91.

12. Johnson RW, Rice AS. Postherpetic neuralgia. N Engl J Med 2014; 371: 1526-33.

13. Schmader K. Herpes zoster. Clin Geriatr Med 2016; 32 : 539-53.

14. Haanpää M, Rice AS, Rowbotham MC. Treating herpes zoster and postherpetic neuralgia. Pain Clin Updates 2015; 23: 1-8. Available at https://s3.amazonaws.com/rdcmsiasp/tiles/production/public/Content/ContentFolders/Publicati ons2/PainClinicalUpdates/Archives/pcu_vol23_no4_may20 15.pdf.

15. Blom S. Trigeminal neuralgia: its treatment with a new anticonvulsant drug (G-32883). Lancet 1962; 1: 839-40.

16. Moore RA, Straube S, Wiffen PJ, Derry S, McQuay HJ. Pregabalin for acute and chronic pain in adults. Cochrane Database Syst Rev 2009: CD007076.

17. Pfizer. Neurontin 2017 [Internet]. New York, NY: Division of Pfizer Inc.; 2017 [cited 2017 Oct 17]. Available at http://labeling.pfizer.com/ShowLabeling.aspx?id=630.

18. Meng FY, Zhang LC, Liu Y, Pan LH, Zhu M, Li CL, et al, Efficacy and safety of gabapentin for treatment of postherpetic neuralgia: a meta-analysis of randomized controlled trials. Minerva Anestesiol 2014; 80: 556-67.

19. Depomed. Gralise 2012 [Internet]. Newark, NJ: Depomed, Inc.; 2012 [cited 2017 Oct 17]. Available at https://www.gralise.com/sites/default/iiles/GRALISE_PI_DEC 2012.pdf.

20. Sang CN, Sathyanarayana R, Sweeney M; DM-1796 Study 
Investigators. Gastroretentive gabapentin (G-GR) formulation reduces intensity of pain associated with postherpetic neuralgia (PHN). Clin J Pain 2013; 29: 281-8.

21. Arbor. Horizant 2016 [Internet]. Atlanta, GA: Arobor Pharmaceuticals, LLC; 2016 [cited 2017 Oct 17]. Available at https://www.horizant.com/assets/docs/Horizant_Prescribi nglnformation.pdf.

22. Lal R, Sukbuntherng J, Luo W, Tovera J, Lassauzet ML, Cundy KC. Population pharmacokinetics and pharmacodynamics of gabapentin after administration of gabapentin enacarbil. J Clin Pharmacol 2013; 53: 29-40.

23. Pfizer. Lyrica 2016 [Internet]. New York, NY: Division of Pfizer Inc.; 2016 [cited 2017 Oct 17]. Available at http:// labeling.pfizer.com/showlabeling. aspx?id=561.

24. Ifuku M, Iseki M, Hidaka I, Morita Y, Komatus S, Inada E. Replacement of gabapentin with pregabalin in postherpetic neuralgia therapy. Pain Med 2011; 12: 1112-6.

25. Zilliox LA. Neuropathic pain. Continuum (Minneap Minn) 2017; 23: 512-32.

26. Hempenstall K, Nurmikko TJ, Johnson RW, A'Hern RP, Rice AS. Analgesic therapy in postherpetic neuralgia: a quantitative systematic review. PLoS Med 2005; 2: e164.

27. Enamandram M, Rathmell JP, Kimball AB. Chronic pain management in dermatology: a guide to assessment and nonopioid pharmacotherapy. J Am Acad Dermatol 2015; 73: $563-73$.

28. Harden RN, Kaye AD, Kintanar T, Argoff CE. Evidencebased guidance for the management of postherpetic neuralgia in primary care. Postgrad Med 2013; 125: 191-202.

29. Derry S, Wiffen PJ, Moore RA, Quinlan J. Topical lidocaine for neuropathic pain in adults. Cochrane Database Syst Rev 2014: CD010958.

30. Grunenthal. Versatis 2015 [Internet]. Buckinghamshire: Grunenthal Ltd.; 2015 [cited 2017 Oct 17]. Available at http://www.medicines.org.uk/emc/medicine/19291/SPC/Ve rsatis\%2b5\%2b\%2bMedicated\%2bPlaster/.

31. Krumova EK, Zeller M, Westermann A, Maier C. Lidocaine patch (5\%) produces a selective, but incomplete block of $A \delta$ and C fibers. Pain 2012; 153: 273-80.

32. Campbell BJ, Rowbotham M, Davies PS, Jacob P 3rd, Benowitz NL. Systemic absorption of topical lidocaine in normal volunteers, patients with post-herpetic neuralgia, and patients with acute herpes zoster. J Pharm Sci 2002; 91 : 1343-50.

33. Navez ML, Monella C, Bösl I, Sommer D, Delorme C. $5 \%$ lidocaine medicated plaster for the treatment of postherpetic neuralgia: a review of the clinical safety and tolerability. Pain Ther 2015; 4: 1-15.

34. Baron R, Mayoral V, Leijon G, Binder A, Steigerwald I, Serpell M. 5\% lidocaine medicated plaster versus pregabalin in post-herpetic neuralgia and diabetic polyneuropathy: an open-label, non-inferiority two-stage RCT study. Curr Med Res Opin 2009; 25: 1663-76.

35. Baranidharan G, Das S, Bhaskar A. A review of the high-concentration capsaicin patch and experience in its use in the management of neuropathic pain. Ther Adv Neurol Disorder 2013; 6: 287-97.

36. Irving GA, Backonja MM, Dunteman E, Blonsky ER, Vanhove GF, Lu SP, et al. A multicenter, randomized, double-blind, controlled study of NGX-4010, a high-concentration capsaicin patch, for the treatment of postherpetic neuralgia. Pain Med 2011; 12: 99-109.

37. Acorda. Qutenza 2013 [Internet]. Ardsley, NY: Acorda Therapeutics, Inc.; 2013 [cited 2017 Oct 17]. Available at http://www.qutenza.com/_docs/qutenza_full_PI_.pdf.

38. Derry S, Rice AS, Cole P, Tan T, Moore RA. Topical capsaicin (high concentration) for chronic neuropathic pain in adults. Cochrane Database Syst Rev 2017: CD007393.

39. Burness CB, McCormack PL. Capsaicin $8 \%$ patch: a review in peripheral neuropathic pain. Drugs 2016; 76: 123-34.

40. Raja SN, Haythornthwaite JA, Pappagallo M, Clark MR, Travison TG, Sabeen S, et al. Opioids versus antidepressants in postherpetic neuralgia: a randomized, placebo-controlled trial. Neurology 2002; 59: 1015-21.

41. Boureau F, Legallicier P, Kabir-Ahmadi M. Tramadol in post-herpetic neuralgia: a randomized, double-blind, placebo-controlled trial. Pain 2003; 104: 323-31.

42. Shackleton T, Ram S, Black M, Ryder J, Clark GT, Enciso R. The efficacy of botulinum toxin for the treatment of trigeminal and postherpetic neuralgia: a systematic review with meta-analyses. Oral Surg Oral Med Oral Pathol Oral Radiol 2016; 122: 61-71.

43. Park J, Park HJ. Botulinum toxin for the treatment of neuropathic pain. Toxins (Basel) 2017; 9: pii: E260.

44. Ding XD, Zhong J, Liu YP, Chen HX. Botulinum as a toxin for treating post-herpetic neuralgia. Iran J Public Health 2017; 46: 608-11.

45. Kim HJ, Ahn HS, Lee JY, Choi SS, Cheong YS, Kwon K, et al. Effects of applying nerve blocks to prevent postherpetic neuralgia in patients with acute herpes zoster: a systematic review and meta-analysis. Korean J Pain 2017; 30: 3-17.

46. Ing MR, Hellreich PD, Johnson DW, Chen JJ. Transcutaneous electrical nerve stimulation for chronic post-herpetic neuralgia. Int J Dermatol 2015; 54: 476-80.

47. Lerman IR, Chen JL, Hiller D, Souzdalnitski D, Sheean G, Wallace $M$, et al. Novel high-frequency peripheral nerve stimulator treatment of refractory postherpetic neuralgia: a brief technical note. Neuromodulation 2015; 18: 487-93.

48. Kim K, Jo D, Kim E. Pulsed radiofrequency to the dorsal root ganglion in acute herpes zoster and postherpetic neuralgia. Pain Physician 2017; 20: E411-8.

49. Kim ED, Lee YI, Park HJ. Comparison of efficacy of continuous epidural block and pulsed radiofrequency to the 
dorsal root ganglion for management of pain persisting beyond the acute phase of herpes zoster. PLoS One 2017; 12: e0183559.

50. Shi $Y$, Wu W. Treatment of neuropathic pain using pulsed radiofrequency: a meta-analysis. Pain Physician 2016; 19: 429-44.

51. Yanamoto F, Murakawa K. The effects of temporary spinal cord stimulation (or spinal nerve root stimulation) on the management of early postherpetic neuralgia from one to six months of its onset. Neuromodulation 2012; 15: 151-4.

52. Ko YK, Lee HY, Lee WY. Clinical experiences on the effect of scrambler therapy for patients with postherpetic neuralgia. Korean J Pain 2013; 26: 98-101.

53. Marineo G, Iorno V, Gandini C, Moschini V, Smith TJ. Scrambler therapy may relieve chronic neuropathic pain more effectively than guideline-based drug management: results of a pilot, randomized, controlled trial. J Pain Symptom Manage 2012; 43: 87-95.

54. Harpaz R, Ortega-Sanchez IR, Seward JF; Advisory Committee on Immunization Practices (ACIP) Centers for Disease Control and Prevention (CDC). Prevention of herpes zoster: recommendations of the Advisory Committee on Immunization Practices (ACIP). MMWR Recomm Rep 2008; 57: $1-30$.

55. Merck. Zostavax 2017 [Internet]. Kenilworth: Merck Sharp \& Dohme Corp.; 2017 [cited 2017 Oct 17]. Available at http://www.merck.com/product/usa/pi_circulars/z/zostavax /zostavax_pi2.pdt.

56. Kang DH, Kim SY, Kim HG, Park JH, Kim TK, Kim KH. Earlier treatment improves the chances of complete relief from postherpetic neuralgia. Korean J Pain 2017; 30: 214-9. 